\title{
Configurações
}

Revista de sociologia

12 | 2013

EPISTEMOLOGIAS DO SUL: Contextos de Investigação

\section{A cegueira em Moçambique: a sul de um sentido}

Blindness in Mozambique: South of a sense

La cécité au Mozambique: le Sud d'un sentimento

\section{Bruno Sena Martins}

\section{(2) OpenEdition}

\section{Journals}

Edição electrónica

URL: http://journals.openedition.org/configuracoes/2003

DOI: $10.4000 /$ configuracoes.2003

ISSN: 2182-7419

\section{Editora}

Centro de Investigação em Ciências Sociais

\section{Edição impressa}

Data de publição: 1 Dezembro 2013

Paginação: $61-74$

ISBN: 1646-5075

ISSN: 1646-5075

\section{Refêrencia eletrónica}

Bruno Sena Martins, "A cegueira em Moçambique: a sul de um sentido », Configurações [Online],

12 | 2013, posto online no dia 14 outubro 2014, consultado o 30 abril 2019. URL : http://

journals.openedition.org/configuracoes/2003; DOI : 10.4000/configuracoes.2003

Este documento foi criado de forma automática no dia 30 Abril 2019.

(c) CICS 


\title{
A cegueira em Moçambique: a sul de um sentido
}

\author{
Blindness in Mozambique: South of a sense \\ La cécité au Mozambique: le Sud d'un sentimento
}

Bruno Sena Martins

\section{Introdução}

1 O presente texto estabelece-se numa relação comparativa com a análise etnográfica, anteriormente realizada, sobre a realidade das pessoas cegas em Portugal; tratou-se de uma análise encetada com o intuito de explorar as relações entre as experiências das pessoas cegas e os valores culturais dominantes através dos quais a cegueira é pensada. A persecução desta relação confrontou-nos com a singular vitalidade da "narrativa da tragédia pessoal" (Oliver, 1990) enquanto gramática de sentido que se apõe às experiências particulares das pessoas cegas. Nestas indagações, em que me demorei noutros momentos (Martins, 2006), interessou-me explorar os significados que a história do Ocidente foi ligando à cegueira e à vida das pessoas cegas. Tanto quanto conhecer os ecos simbólicos e valores sedimentados que permanecem connosco desde a Grécia Antiga, ou desde o mundo hebraico que nos legou a Bíblia, importava perceber de que modo a modernidade ressignificou a cegueira enquanto defi ciência visual, à luz da biomedicina moderna. Se o advento do sistema Braille exprime aquilo que foi promessa moderna à cegueira - uma promessa de emancipação social -, a invenção da deficiência coloca-nos perante uma reinvenção da exclusão social. Ou seja, a modernidade ocidental, naturalizando a inferioridade no corpo individual, feito patológico, reinventa a cegueira através de conceções que perpetuam uma longa história de desqualificação simbólica que nos segue há tanto tempo quanto a tragédia de Édipo.

2 Partindo desse trabalho prévio, a exploração empírica do contexto moçambicano que aqui nos ocupará definiu-se, fundamentalmente, com o objetivo de aceder a contextos da cegueira que prometessem ser desafiadores da historicidade que define o percurso dos 
valores que no Ocidente foram sendo apostos à experiência de quem não vê. Tratava-se, pois, de valorizar um diferente quadro epistémico, por assim dizer, "contra o texto" hegemónico que naturalizou a cegueira como tragédia e como "deficiência visual" na modernidade ocidental. A ideia, dominante em Moçambique, de que o significado da cegueira necessariamente convoca as relações com os espíritos e dinâmicas imanentes à feitiçaria surge, talvez, como proverbial expressão do "circuito do mesmo" em que tantas vezes se movem os nossos questionamentos. Portanto, o exercício de viagem etnográfica arquitetado entre as vivências das pessoas cegas no contexto português e no contexto moçambicano nutriu-se de uma hipótese eminentemente epistemológica: a cegueira pode ser diferentemente representada no quadro de uma matriz de significado não ocidental.

3 Moçambique surgiu, assim, como ensejo para uma análise empírica passível de se constituir enquanto parte de uma crítica cultural ancorada numa desfamiliarização, uma exotização do ponto de partida capaz de forjar um "repatriamento cultural" (Marcus e Fischer, 1999).

4 Viajar para Sul, no sentido em que me proponho, implica reconhecer de que modo a empresa etnográfica se inscreve num mundo marcado por relações de poder:

De facto, o trabalho etnográfico tem estado enredado num mundo de duradouras e mutáveis desigualdades de poder, e continua a estar nele implicado. Mas o seu papel nessas relações de poder é complexo, frequentemente ambivalente, potencialmente contra-hegemónico. (Clifford, 1986: 9)

5 Essa disposição epistemológica - que também é a negação da sobranceria civilizadora em que assentou muito do discurso colonial e que ainda define muito da relação do Ocidente com o resto do mundo - é bem captada por Boaventura de Sousa Santos (2000: 242), quando preconiza a necessidade de se "aprender com o Sul" como forma de superação da razão metonímica ${ }^{1}$ que a modernidade ocidental abraçou. A ideia e o imperativo de aprender com o Sul constituem-se como uma poderosa metáfora, em tudo congruente na invocação que o autor faz de uma "epistemologia das ausências" que nos permite aceder a conhecimentos alternativos que não chegaram a ocorrer porque foram impedidos de surgir, e a alternativas que foram marginalizadas e desqualificadas (Santos, 2000: 225).

Centrados na questão da cegueira, aprender com o Sul implica, em primeiro lugar, descodificar os números que nos dão conta da existência de cerca de 314 milhões de pessoas com baixa visão no mundo, das quais mais de 45 milhões serão cegas (OMS, 2009). Essas estimativas são tanto mais significativas quanto tivermos em conta que $80 \%$ das formas de deficiência visual poderiam ter sido prevenidas ou curadas, pelo que a sua incidência não pode deixar de refletir as assimetrias socioeconómicas no mundo (ibid.). Isso ficou bem patente no trabalho de campo que realizei em Moçambique: as formas de cegueira a cuja origem acedi são esmagadoramente devidas a precárias condições sanitárias, nutritivas e médicas, com particular destaque para as doenças infeciosas e, nestas, para as muitas formas de cegueira causadas pelos exantemas da infância (sarampo, varicela, rubéola, etc.). E se é verdade que nos países desenvolvidos a incidência de deficiências tem tendência para aumentar em função do envelhecimento da população, também é verdade que a fronteira entre Norte e Sul fi ca irremediavelmente marcada pela noção de "deficiências evitáveis", ou seja, as formas de deficiência que têm na sua génese carências de ordem socioeconómica e que, não fossem essas carências, poderiam ter sido prevenidas/debeladas.

7 Em segundo lugar - elemento crucial neste trabalho -, investigar a cegueira em contextos do sul global implica reconhecer o modo como a nossa noção de "cegueira como 
deficiência visual" pode ser posta em causa por conceções de saberes que a ciência moderna e a ordem colonial desqualificaram. No fundo, invertendo os termos da arrogância moderna ocidental, propomo-nos aprender com os espíritos do lugar (Martins, 2013).

\section{A cegueira no espírito do lugar}

8 Foi ainda em Portugal que fi $\mathrm{z}$ a primeira entrevista a um moçambicano cego, Isildo, na altura um estudante da Escola Superior de Educação de Coimbra, com quem estava familiarizado pela sua presença regular nas instalações da Associação de Cegos e Amblíopes de Portugal. Com evidente intuito preparativo da minha ida para Moçambique dali a uns meses, questionei Isildo sobre alguns dos aspetos que marcam as experiências da cegueira em Moçambique, naturalmente ciente de que a sua vivência pessoal estaria enriquecida pela longa proximidade e coabitação com uma pletora de outras histórias da cegueira. Um desses aspetos incidia sobre as causas que comummente se associavam ao surgimento de uma situação de cegueira, e a resposta de Isildo foi retumbante em relação à presença da feitiçaria como primordial elemento explicativo:

$\mathrm{Eu}$ até generalizava isso. Em Moçambique não há cegueira sem causas: sempre porque fulano X enfeitiçou. E isso até cria revolta. Não é a família que vai rejeitar o cego, mas é o cego que vai rejeitar aquela pessoa que fez o feitiço. E isso tem acontecido muitas vezes. Por exemplo, nesse colégio onde eu estive havia pessoas lá internadas que tinham alguns familiares na própria cidade [na Beira], mas que se recusavam a ir para casa deles porque achavam que tinham sido eles a enfeitiçar. Nessas sociedades a cegueira, como todas as doenças, tem sempre outra explicação. (Entrevista pessoal)

9 Para uma sensibilidade epistemológica marcada por alguns dos proverbiais trabalhos da antropologia, seria difícil não entrever nas palavras de Isildo sobre a cegueira em Moçambique um curioso eco das célebres palavras de E. E. Evans-Pritchard sobre os azandes em Witchcraft, Oracles and Magic Among the Azande (obra originalmente publicada em 1937): "A noção de feitiçaria explica eventos infelizes" (Evans-Pritchard, 1997: 303). E se é verdade que são várias e longas as viagens que nos levam das palavras de EvansPritchard às de Isildo, também é verdade que permanece a persuasão de que, num caso e noutro, as explicações socioespirituais para o infortúnio correspondem, grosso modo, a uma cosmovisão partilhada, cuja hegemonia e ubiquidade tive oportunidade de conhecer em Moçambique. Estamos perante um conjunto de dinâmicas sociais em que ressalta o modo como o mal físico é socialmente interpretado como tendo uma causa socioespiritual, - normalmente um feitiço perpetrado por um familiar, vizinho ou colega de trabalho -, e em que é conferida inequívoca centralidade ao praticante da dita medicina tradicional enquanto agente detentor de poderes e saberes que são a um tempo divinatórios (no identificar da causa socioespiritual) e curativos (no desfazer do mal físico).

10 Com diferentes designações nas línguas locais moçambicanas², este ator foi quase sempre identificado em português pelos entrevistados - e seus tradutores - como "curandeiro". Usarei esta mesma designação no texto, quer para evitar mergulhar nas especificidades e diferenças das diversas designações usadas nas línguas moçambicanas, quer para evitar as designações "médico tradicional" ou "praticante de medicina tradicional". Sendo expressões analíticas fundamentais para analisarmos o lugar a que a medicina moderna ocidental quis relegar os saberes dos curandeiros, pretendo evitar os termos da oposição 
entre moderno e tradicional, por duas razões. Primeiro, porque essa dicotomia não surge como uma oposição relevante nos percursos de vida e nos discursos das pessoas que entrevistei (interagi quase sempre com a perspetiva dos clientes dos serviços dos curandeiros); segundo, porque o "tradicional" corrobora uma visão eurocêntrica em que os saberes dos curandeiros são vistos como estáticos, homogéneos e como expressões de um primitivismo pré-letrado e pré-moderno (Honwana, 2003: 23; Meneses, 2004: 81).

Uma vez no terreno, procurei compreender mais sobre a relação entre a cegueira e o conjunto de crenças e práticas comummente associadas ao fenómeno da feitiçaria, relação que inicialmente se indiciava como um dos aspetos mais decisivos no contraponto às leituras ocidentais dominantes acerca da cegueira. Esse facto acabou por ser fortemente reforçado no contexto das histórias de vida pela quase invariável presença da questão da feitiçaria, sem a qual sistematicamente fracassaríamos em compreender o quadro social em que cada cegueira é entendida: seja como facto da vida cuja causalidade define aquilo que a cegueira é para os atores que lhe dão significado, seja como maleita que se tenta superar através de práticas ativas que tomam como ponto de partida o feitiço que a originou.

Convém referir desde já que, quando aqui refiro feitiçaria como causa da cegueira, falo de feitiçaria num sentido lato que, na verdade, refere todo um conjunto de fenómenos que nos remetem para dinâmicas que têm em comum a presença dos espíritos no mundo dos vivos. Poderei dizer, pois, que refiro a feitiçaria num sentido próximo daquele que Marc Augé lhe atribui em certo momento:

Falar de feitiçaria, efectivamente, é designar um conjunto de crenças estruturadas e partilhadas por uma dada população acerca da origem da infelicidade, da doença ou da morte, e o conjunto das práticas de detecção, de terapia e de sanções que correspondem a estas crenças. (Augé, 2000: 72)

Trata-se, sim, de uma etiologia que percebe o acometimento da cegueira a partir daquilo a que, em favor da explicitação - ainda que redundantemente -, chamo causas socioespirituais. Tal como a leitura mais corrente nos envia para um feitiço perpetrado por (ou realizado a mando de) familiares, vizinhos e familiares que tentam infligir mal por inveja, vingança, disputas, etc., também a cegueira pode decorrer igualmente de outras lógicas. Sem pretender ser exaustivo, referirei algumas das lógicas causais da cegueira com que tomei contacto, através das histórias de vida que me foram confiadas e através das reflexões dos sujeitos sobre estas mesmas dinâmicas:

- pode resultar da perda de proteção dos espíritos antepassados devido a um incumprimento ritual. Nos diversos momentos significativos da vida, os vivos devem prestar continuado respeito aos espíritos, através de celebrações rituais ou de um cuidado vigilante para não infringir prescrições na harmonia com os ancestrais. Quando tal não acontece, além de poderem retirar proteção, vulnerabilizando a família incumpridora a maleitas várias, os espíritos linhageiros podem punir ativamente a omissão;

15 - pode resultar da falta de respeito ritual em relação aos espíritos de determinado território ou do incumprimento de normas locais (por exemplo, se ao mudar de residência a família não "fechou a casa" de acordo com o ritual local, poderá sofrer represálias); pode resultar da ação vingativa de alguém que, após a morte, passa a ser um espírito com o particular poder de intervir no mundo dos vivos para com eles ajustar contas e fazer exigências (nos espaços em que me movi, essa capacidade era quase sempre designada de $m p h f u k w a^{3}$, sendo a etnia ndau particularmente temida em Moçambique enquanto detentora deste poder); 
16 • pode resultar do incumprimento de uma "noiva ou mulher do espírito" relativamente às obrigações impostas pelo seu matrimónio (as mulheres do espírito são jovens solteiras oferecidas em matrimónio pela própria família a um espírito, de modo a apaziguar o desejo de vingança deste em relação a essa família);

17 - pode resultar da ação do espírito de um antepassado que inflige determinada maleita para poder comunicar com a família. Nesse caso, a ida ao curandeiro em busca da causa do problema funciona como dispositivo para colocar a família em contacto com o espírito do antepassado - normalmente por via de fenómenos de possessão pelos espíritos;

18 - pode resultar da ação de um antepassado que, tendo sido curandeiro, deseja que um seu descendente (normalmente neto) siga a sua tradição e se torne, também ele, um curandeiro. Neste sentido, ele provoca aquilo que às vezes se designa de "doença do chamamento" (cf. e. g. Honwana, 2003: 87 ss; Meneses, 2004: 89-89; Granjo, 2009: 575);

19 - pode resultar da ambição de um familiar próximo que, em busca de riqueza, de prestígio ou de quaisquer outros benefícios pessoais, recorre a um curandeiro/feiticeiro para fazer uma "droga" cuja eficácia depende, como moeda de troca, da sua disponibilidade para sacrificar a vida ou a saúde de um familiar próximo.

20 Procuro assim identificar, em traços largos, toda uma série de possíveis itinerários causais da cegueira na sua relação com a feitiçaria e com os espíritos, conforme me foram sendo relatados na experiência de terreno. Se é verdade que os processos acima sistematizados correspondem às etiologias de doença que, de uma forma generalista, poderão ser associadas a muitas sociedades africanas, também importa reconhecer que a relação com os espíritos é sempre o produto de especificidades, seja em função do grupo sociolinguístico, seja em função da história local (a ecologia, o impacto dos conflitos armados, as diferentes atividades de subsistência, a história política, as tradições cerimoniais específicas, as tensões que estruturam determinado quadro social). Ou seja, cabe reconhecer as práticas de feitiçaria enquanto realidade dinâmica fortemente marcada pelas historicidades particulares. Exemplo disto é o modo como em Espíritos Vivos, Tradições Modernas (2003) Alcinda Honwana analisa a possessão pelos espíritos entre os tsongas no Sul de Moçambique. Nesse texto Honwana pertinentemente contempla fenómenos histórico-políticos estruturantes das dinâmicas da feitiçaria, fenómenos tão diversos como o domínio nguni, a presença ndau, o colonialismo português, as emigrações para a África do Sul, as conversões ao cristianismo, os conflitos armados, a reintegração social pós-guerra, etc.

21 A minha abordagem às histórias de vida, feita que foi em diferentes lugares de Moçambique, de pessoas de diferentes pertenças sociolinguísticas, e pessoas cujas vidas frequentemente se moveram no mapa, não tem a pretensão de ser exaustiva ao ponto de tratar de modo sistemático as diferenças existentes nas várias cosmologias de sentido.

Ao longo do trabalho de terreno, fui-me apercebendo da fulcral importância da feitiçaria não tanto porque os meus interlocutores no terreno chamassem a atenção para essa dimensão; mas sim porque a saliência da relação entre cegueira e feitiço - para a qual Isildo já me havia chamado a atenção - fez crescer em mim essa sensibilidade hermenêutica. De facto, a menos que eu colocasse perguntas diretas, mostrando algum conhecimento sobre os padrões das dinâmicas sociais em jogo, os factos sociais iam-me sendo apresentados numa versão que correspondia às lógicas que se supunham passíveis de serem entendidas por um português recém-chegado a Moçambique. Na medida em que os entrevistados me configuravam como um investigador português pouco conhecedor 
das lógicas locais, as suas histórias de vida (em particular, histórias de cegueira) eram-me contadas numa narrativa que omitia qualquer referência às dinâmicas socioespirituais que pudessem estar na origem da cegueira e, frequentemente, no processo de busca de cura ("fiquei cego por causa de um sarampo"). Só quando diretamente interpunha uma questão sobre os feitiços e os espíritos que poderiam ser causa da cegueira é que os entrevistados expunham toda uma pletora de questões a esse respeito ("ah, sim, foi um sarampo de feitiço"). Frequentemente, a resposta à interpelação está próxima desta que aqui cito: "Já sabe, nós somos africanos e aqui em África essas coisas não podem faltar." Esta resposta sistemática é esclarecedora sobre uma perceção que localiza as explicações socioespirituais para o mal físico na realidade africana. A capacidade para omitir ou incluir as "coisas africanas" nas histórias associadas à cegueira é reveladora de uma sedimentada noção, quer das fronteiras das diferentes lógicas paradigmáticas em jogo, quer dos valores hegemónicos que consagram a validade global da biomedicina e remetem a atividade dos espíritos e dos curandeiros para um exótico africano. Ou seja, existe a plena noção da hegemonia de uma perspetiva ocidental - hegemonia historicamente alicerçada no colonialismo - que desqualifica, "localizando", os valores, saberes e crenças associados àquilo que comummente se coloca sob o chapéu da medicina tradicional africana.

Assim, os itinerários terapêuticos das pessoas cegas deixam patente a disposição dos indivíduos para se moverem entre diferentes possibilidades terapêuticas de acordo com convicções de eficácia e com a acessibilidade. Ao contrário do que se podia supor, a naturalidade desse movimento entre lógicas terapêuticas diversas (grosso modo, as biomédicas e as socioespirituais) acontece sem que isso implique a ausência de reconhecimento da diferença paradigmática dos diferentes paradigmas terapêuticos que o colonialismo tornou contíguos. O facto é que os sujeitos estão cientes das diferentes origens históricas desses paradigmas e cientes das assimetrias de poder e das linhas de fronteira que foram definidas a partir dessas mesmas assimetrias. Ou seja, na realidade em questão, a busca de cura ou de explicação para a cegueira acede pragmaticamente a lógicas que se reconhecem diferentes ("as nossas coisas africanas" e "os médicos do hospital") e que são diferentemente prestigiadas na conceção de modernidade definida e imposta pelo Ocidente.

24 A noção de "cegueira de feitiço" foi amiúde referida para descrever uma cegueira que, não obstante ter causas próximas identificáveis (sarampo, um acidente de viação, o rebentamento de um explosivo, etc.), é pensada como produto de dinâmicas espirituais a montante. Nesse sentido, além da busca de cura, o processo de indagação desencadeado pelo acometimento de uma cegueira comporta uma inquirição sobre as relações socioespirituais, bem como uma busca de "segurança ontológica" (Giddens, 1995) que não se prende apenas com a busca da visão, mas igualmente com a confiança na vida social confiança posta em causa pela vulnerabilidade que se terá substanciado na cegueira. A imanência das "medicinas tradicionais" à realidade social moçambicana confere-lhes um papel não replicável, enquanto instâncias capazes de, além da cura, devolverem a "segurança ontológica", pela centralidade fenomenológica da visão mas também pela necessidade de confrontar as tensões socioespirituais na origem do mal. 


\section{Resistências situadas} experiências das pessoas cegas colidem com a gramática dominante da cegueira como tragédia pessoal e, por conseguinte, com os estigmas que conotam a cegueira ora com a incapacidade, ora com a tragédia (Martins, 2006). Este embate impõe que a valorização pessoal das pessoas cegas passe por uma ressignificação da cegueira, em que a noção de tragédia é recusada a favor de uma afirmação contra-hegemónica das capacidades e da riqueza dos mundos que coexistem com o facto de "não ver".

Moçambique, as resistências nas histórias de cegueira erigem-se contra um outro tipo de construções hegemónicas, construções essas que, em larga medida, situam as pessoas cegas noutro paradigma epistémico. Referimo-nos, claro, a uma leitura etiológica, dominante em Moçambique, que entende a cegueira como produto de dinâmicas socioespirituais. No contexto moçambicano, o conceito de deficiência surge apenas nominalmente, a partir das intuições recentes, de matriz ocidental, sem que tenha um eco culturalmente significativo.

Ali o que se configura como hegemonia é, de facto, o vínculo entre cegueira e feitiço. No entanto, a força cultural das leituras que entendem a cegueira como produto de feitiço não tem por correlato a formação de um conjunto de significados estáveis para aquilo que a cegueira é; e isto por duas razões.

Primeiro, porque cada cegueira resulta de uma história social específica: o feitiço de um familiar rancoroso, a vingança de um espírito inimigo, o chamamento de um espírito ancestral, uma transgressão ritual, etc. Além do mais, essa história específica tem uma dimensão social, mas não uma dimensão pública: a tensão socioespiritual na origem da cegueira, quando é conhecida de forma mais ou menos estável, tende a ficar cingida ao domínio das relações familiares próximas da pessoa cega. Nesse sentido, o facto de a sociedade envolvente supor invariavelmente que uma situação de cegueira é precedida por um feitiço não equivale a dizer que a narrativa desse feitiço seja conhecida no quadro social mais amplo. $O$ vínculo entre as dinâmicas socioespirituais e a cegueira, sendo um dado que se trivializa naquele paradigma, permanece oculto nos seus contornos particulares com exceção para os diretamente implicados (eventuais perpetradores), relações próximas da pessoa cega, e para os curandeiros chamados à liça - profissionais envolvidos para desvendar a origem do feitiço.

Em segundo lugar, ao contrário da narrativa histórica da deficiência visual, o vínculo entre a cegueira e eventos socioespirituais concede uma causalidade e define a origem da cegueira a partir das relações sociais, mas nada nos diz sobre aquilo que a cegueira é ou implica, nem sobre o fechamento vivencial que dela decorre. À luz desta matriz cultural, há uma homologia entre as implicações da cegueira, deixadas em aberto, não postas em cultura para além da noção do infortúnio, e a multitude de narrativas sociais que poderão ter estado na sua origem. Ou seja, mesmo havendo uma leitura hegemónica que ancora a causalidade da cegueira a dinâmicas socioespirituais, essa hegemonia não tem um efeito normativo no sentido de aspirar a totalizar o significado da cegueira em preconceções estabilizadas. Nessa medida, a linguagem da resistência e das narrativas contrahegemónicas que empregamos para o contexto português em Moçambique assume mais o sentido de negociação, numa lógica em que ora se abraçam as implicações da origem socioespiritual da cegueira, ora se cria em relação a elas um distanciamento pragmático 
(distanciamento no curso da ação dos indivíduos, já que as convicções permanecem inamovíveis).

Um quadro cultural em que as leituras hegemónicas que apreendem a cegueira não a definem numa qualquer especificidade prévia mostra-se mais permeável a narrativas situadas: a associação entre mendicidade e cegueira oferecida pelos recentes processos de urbanização e desestruturação do espaço rural; a emergência de cegos qualificados com prestígio e projeção social a partir do Instituto de Deficientes Visuais da Beira; e as narrativas individuais forjadas em contextos comunitários circunscritos, em que frequentemente assistimos à possibilidade de as pessoas cegas se afirmarem como elementos produtivos e prestigiados no seio da comunidade. De facto, sobretudo nos espaços rurais, é muito comum as crianças cegas terem uma noção tardia da sua diferença em relação às demais:

Ficava em casa e brincava, ia correr com os meus amigos e ia já pastorar o cabrito, boi. Eu perseguia os meus companheiros, andava com eles na rua, ia recolher a água ao rio Zambeze. (Rosário Robate, entrevista pessoal)

31 Temos, pois, narrativas em que a diferença não é fixada, e cujas possibilidades de inclusão, mormente nas atividades produtivas, se movem em contextos que são mais afeitos a aceitar a pessoa cega como igual do que a reconhecê-la como diferente. Assim, por um lado, temos os benefícios da aceitação social sem discriminação e, por outro, temos a contingência que resulta da ausência de abordagens específicas mobilizadas para ensinar a pessoa (ou a criança) cega de acordo com as suas particularidades.

Ante a gramática dominante das causas socioespirituais, a "resistência" que se denota nas histórias de cegueira é aquela que se relaciona, por um lado, com a aceitação da irreversibilidade da cegueira e, por outro, com a capacidade de abdicar da busca de vingança, ou seja, abdicar da retaliação em relação aos eventuais culpados pelo feitiço que desencadeou a cegueira. Estes processos, frequentemente concomitantes e que muito se relacionam com o cessar da peregrinação por curandeiros, têm alguma analogia com o momento que no contexto português frequentemente se designa por "assumir a cegueira".

No contexto português, esse assumir da cegueira tem a forma de uma afirmação identitária contra os estigmas que tendem a menorizar a pessoa cega; já no contexto moçambicano, assumir a cegueira é, no fundo, assumir viver como pessoa cega, ao mesmo tempo que se colocam para trás das costas as cogitações acerca das causas da cegueira. Resistir ao paradigma cultural dominante em Moçambique é deixar de ser a vítima de um feitiço em busca de cura e de culpados para passar a ser uma pessoa cega cuja vida prossegue apaziguada a jusante de respostas por esclarecer, a despeito de vinganças por cumprir. A etiologia cultural da cegueira em Moçambique não é totalizante porque não define a cegueira com um significado estável. Ao invés, a identificação de causas socioespirituais na origem de cada cegueira produz perspetivas abertas no sentido em que: a) a causalidade não define culturalmente as implicações da cegueira; b) cada cegueira tem a sua origem social ligada a um feitiço particular, e essa origem não é necessariamente um dado cultural público; $c$ ) o significado da cegueira é mais permeável a narrativas recentes, sejam as histórias pessoais da cegueira, sejam as estruturas que ancoram a cegueira e suas implicações a arquipélagos de sentido recentemente sedimentados. 


\section{Conclusão: o corpo múltiplo}

Numa instigante etnografia realizada num hospital holandês, Annemarie Mol (2002) leva a cabo uma minuciosa investigação sobre os processos quotidianos de tratamento e cura da arteriosclerose. Percorrendo no mesmo hospital as diversas instâncias em que as práticas médicas se ocupam desta doença, inquirindo sintomas, medindo, analisando, visualizando, intervindo, Mol verifica como o mesmo corpo é diferentemente "performado" (enacted). Por exemplo, o corpo considerado na clínica define-se através de discursos e dispositivos diversos, que, por isso, não definem o mesmo objeto:

As práticas de performação [enacting] da arteriosclerose clínica e da arteriosclerose patológica excluem-se mutuamente. As primeiras requerem um paciente que se queixe de dores nas pernas. As segundas requerem uma secção transversal de uma artéria visível no microscópio. Essas exigências são incompatíveis, pelo menos não podem ser realizadas simultaneamente. [...] A incompatibilidade é uma questão prática. É uma questão de pacientes que falam por oposição a partes do corpo que são seccionadas. De falar de dor por oposição a estimar o tamanho das células. De colocar questões por oposição a preparar "slides". No ambulatório e no departamento de patologia a arteriosclerose é feita diferentemente. (2002: 35-36, itálico no original) fragmentado, mesmo se é múltiplo, também se mantém junto” (2002: 55). A viagem da cegueira por nós encetada a sul confronta-nos, alego, com um corpo múltiplo. Em primeiro lugar, o corpo múltiplo surge no modo como os processos de busca de cura concebem a mesma cegueira como produto de dinâmicas socioespirituais e como produto de condições patológicas diagnosticadas pela biomedicina. Ou seja, o modo como um mesmo itinerário terapêutico se move tantas vezes entre médicos e curandeiros, entre o paradigma biomédico e o socioespiritual, negociando recursos e mobilizando capitais de confiança, expressa bem como diferentes cegueiras são também uma só (por exemplo, a cegueira causada por um "sarampo de feitiço"). As explicações socioespirituais configuram causalidades complementares, abordagens curativas diferentes, sem que quebrem o elo no modo como determinada cegueira é pensada. Ou seja, se determinada cegueira é o produto de cataratas, e o produto de um feitiço do vizinho, ela poderá ser curada tanto por uma operação às cataratas como por um tratamento que invoque espíritos para reverter o efeito do feitiço.

Mas a cegueira que emerge das histórias de vida em Moçambique conforma-se ainda com a ideia de corpo múltiplo pelo modo como diferentes explicações socioespirituais se identificam na origem de uma mesma cegueira. Se idealmente a consulta de curandeiros permitiria identificar a causa da cegueira, o que se verifica, muitas vezes, é que as diferentes suspeitas e versões oferecidas pelos curandeiros poderão permanecer sem que se deslinde uma resposta definitiva; o facto de nenhuma dessas narrativas ficar inequivocamente estabelecida permite que várias hipóteses permaneçam válidas dentro de uma hermenêutica da suspeita em aberto. Conforme me pude aperceber em muitas entrevistas em que as causas socioespirituais iam sendo desfiadas enquanto hipóteses sobreviventes, uma mesma cegueira pode ficar etiologicamente ancorada a várias hipóteses explicativas cujos termos e implicações não se excluem cabalmente.

Mas a noção de corpo múltiplo que recrutámos da escrita de Annemarie Mol é aqui mobilizada para os dados recolhidos em Moçambique ainda numa outra perspetiva.

Configurações, 12 | 2013 
Refiro-me à leitura de viagem de retorno, naquilo a que poderíamos chamar repatriamento da cegueira. A partir do confronto com a realidade moçambicana, os significados que no Ocidente ancoram a experiência das pessoas cegas (definindo a materialidade dos seus corpos através do idioma da deficiência) são expostos naquilo que é a sua contingência cultural. O corpo múltiplo, nesta aceção, exprime como a biomedicina moderna oferece apenas uma versão para definir a materialidade da cegueira. A objetificação da cegueira enquanto forma particular de patologia - a deficiência visual -, a naturalização da cegueira enquanto condição cujas implicações dizem respeito ao corpo físico, são processos de fechamento de sentido destabilizados pela ideia, etnograficamente sedimentada, de que o corpo da pessoa cega é, afinal, um corpo múltiplo. Um corpo cujos significados e implicações variam, seja entre diferentes paradigmas culturais, seja pelo modo como convocam as (e se inscrevem nas) relações sociais proverbialmente dinâmicas. Esta variação não nega a materialidade da cegueira, não abastece o idealismo da desincorporação do significado; afinal, a espessura material da cegueira - a sua implicação fenomenológica ao nível da experiência incorporada, a impossibilidade de ver - é aquilo que "mantém junto" o corpo múltiplo; é aquilo que, nas palavras de Annemarie Mol, o faz ser "mais do que um e menos que muitos" (2002: 55).

o facto de o significado da cegueira em Moçambique depender tão marcadamente das relações sociais (ou socioespirituais) confronta a noção ocidental de que a cegueira é algo apenas relativo ao corpo físico, suas funções e órgãos.

Nesse sentido, as histórias de espíritos e feitiços convocados por qualquer narrativa pessoal de cegueira expõem a singularidade cultural que, na modernidade ocidental, construiu a deficiência enquanto natureza corpórea que nada deve às construções socioculturais. Como refere Judith Butler, não apenas os corpos tendem a indicar um mundo para além deles, como esse movimento para fora dos seus limites mostra ser central para o que os corpos "são" (1993: ix). Assim, a nomeação e interpretação das alterações e diferenças nos corpos é sempre um processo eminentemente social - mesmo quando se trata do corpo forjado pela biomedicina moderna -, ainda que essa elaboração conduza a uma naturalização do sentido capaz de o subtrair das relações sociais que o geram.

40 As histórias de cegueira movem-se dentro de esquemas de inteligibilidade que demasiadas vezes lhes instauram habitats povoados por modos estreito de conceber a experiência. Ao contrário do que muitos preconceitos fazem crer, a forma como as pessoas cegas habitam as suas sociedades está longe de refletir qualquer estreitamento produzido pela ausência de um sentido (a visão); reproduz sim formas estreitas (produtoras de exclusão e marginalidade) de conceber a diferença no seu modo de ser na vida. Na verdade, a cegueira é frequentemente dobrada a uma relação íntima com muitas das formas de sujeição em que repousam as mais firmes certezas sociais, carregando, portanto, de modo desproporcionado a experiência de lugares que, à vez, são pouco conhecidos e centrais à ordem social. A valorização das experiências das pessoas cegas, seja para regenerar as formas de organização social, seja para a alargar a inteligibilidade acerca das diferenças que animam a vida humana, forja-se como um desígnio que reclama culturas menos certas dos seus sentidos, e corpos viajados onde antes moravam antiquíssimas tragédias.

41 Ao contemplarmos a realidade moçambicana e ao analisarmos como a cegueira ganha sentido em função das dinâmicas dos espíritos do lugar, colocamos a cegueira no contexto cultural que lhe dá significado, que a "materializa" na vida social. A ideia de que a 
cegueira é o produto de dinâmicas sociais que a engendram através de feitiços confrontanos com a contingência cultural dos significados que lhe podem ser associados em determinado quadro cultural. Mas serve igualmente como explicitação - literal ou metafórica - de um vínculo que opera em todo o lugar: os corpos e as suas diferenças jamais escapam às relações sociais que lhes dão sentido. Deste modo o "feitiço" com que a modernidade ocidental forjou a noção hegemónica de cegueira é posto no seu lugar.

\section{BIBLIOGRAFIA}

AUGÉ, Marc (2000), “As crenças na feitiçaria”, in Marc Augé (org.), A Construção do Mundo: Religião, representações, ideologia. Lisboa: Edições 70.

BUTLER, Judith (1993), Bodies That Matter: On the Discursive Limits of Sex. Nova Iorque: Routledge. CLIFFORD, James (1986), “Introduction: Partial truths", in James Clifford (org.), Writing Culture: The poetics and politics of ethnography. Berkeley: University of California Press, 1-26.

EVANS-PRITCHARD, E. E. (1997), “The notion of witchcraft explains unfortunate events”, in Roy Richard Grinker \& Christopher Burghard Steiner (orgs.), Perspectives on Africa: A reader in culture, history, and representation. Cambridge: Blackwell, 249-256.

GIDDENS, Anthony (1995), As Consequências da Modernidade. Oeiras: Celta.

GRANJO, Paulo (2009), “Saúde e doença em Moçambique”, Saúde Soc. São Paulo, 18 (4), 567-581.

HONWANA, Alcinda Manuel (2003), Espíritos Vivos, Tradições Modernas. Lisboa: Ela por Ela.

MARCUS, George; FISCHER, Michael (1999), Anthropology as Cultural Critique: An experimental moment in the human sciences. Chicago: University of Chicago Press.

MARTINS, Bruno Sena (2006), E Se Eu Fosse Cego?: Narrativas silenciadas da defi ciência. Porto: Afrontamento.

MARTINS, Bruno Sena (2013), Sentido Sul: A cegueira no espírito do lugar. Coimbra: Almedina.

MENESES, Paula (2004), "Quando não há problemas, estamos de boa saúde, sem azar nem nada: para uma concepção emancipatória da saúde e das medicinas”, in Boaventura de Sousa Santos \& Teresa Silva (orgs.), Moçambique e a Reinvenção da Emancipação Social. Maputo: Centro de Formação Jurídica e Judiciária.

MOL, Annemarie (2002), The Body Multiple: Ontology in Medical Practice. Durham: Duke University Press.

OLIVER, Michael (1990), The Politics of Disablement. Houndmills: The Macmillan Press.

SANTOS, Boaventura de Sousa (2000), Crítica da Razão Indolente: Contra o desperdício da experiência. Porto: Afrontamento. 


\section{NOTAS}

1. “... a razão metonímica, que se reivindica como a única forma de racionalidade e, por conseguinte, não se aplica a descobrir outros tipos de racionalidade ou, se o faz, fá-lo apenas para as tornar em matériaprima" (Santos, 2002: 240).

2. Designações que não expressam apenas diferenças regionais e etnolinguísticas, mas, igualmente, especificidades nas atribuições dos vários "médicos tradicionais". Vide, por exemplo, a distinção que Alcinda Honwana (2003) estabelece entre os tinyangas e os nyamusoros no Sul de Moçambique.

3. "Mpfhukwa: é um termo derivado do verbo kupfhukua que signifi ca ser acordado, ressuscitar e que indica «uma pessoa que foi ressuscitada entre os mortos. [...] Aparentemente o fenómeno mphfukwa é originalmente Ndau. Esta capacidade é adquirida através dos poderes de uma planta chamada mvhuko, cuja utilização dos poderes faz parte da tradição dos vaNdau. Uma solução feita com base nessa planta era geralmente administrada aos bebés para os proteger. Acredita-se que tal solução torna as pessoas mais fortes e, depois de mortas, capazes de reavivar o seu espírito e procurar vingança." (Honwana, 2003: 62)

\section{RESUMOS}

Viajando a sul, ao encontro da realidade das pessoas cegas em Moçambique, o autor analisa as implicações de uma conceção de cegueira intimamente ligada às dinâmicas socioespirituais. 0 presente artigo fala-nos de um quadro cultural em que, no limite, "não há cegueira sem feitiço". A partir de uma incursão etnográfica entre as "vidas da cegueira", o autor faz emergir um corpo múltiplo que põe no lugar o "feitiço" através do qual a modernidade ocidental inventou a noção de deficiência. Trata-se de um percurso que procura pôr a cegueira no contexto de resistências situadas: corpos e histórias que reclamam por culturas menos certas dos seus sentidos.

Travelling south to find the reality of blind people in Mozambique the author analyses the implications of a conception of blindness closely linked with socio-spiritual dynamics. This paper tells us about a cultural framework in which, ultimately, "there is no blindness without witchcraft". Based on an ethnographic foray into the "lives of blindness", the author brings to light a multi-faceted corpus that puts in place the "witchcraft" through which Western modernity invented the notion of disability. It is a path that attempts to put blindness in the context of installed resistance: corpora and histories that demand cultures less certain of their senses.

Voyageant vers le Sud pour connaître la réalité des personnes aveugles au Mozambique, l'auteur examine les implications d'une conception de la cécité étroitement liée à la dynamique sociospirituelle. Cet article nous parle d'un cadre culturel dans lequel, à la fin, «il n’y a pas de cécité sans sorcellerie». À partir d'une inclusion ethnographique parmi les « vies de la cécité » l'auteur fait émerger un corps multiple qui défi nit la sorcellerie grâce à laquelle la modernité occidentale a inventé le concept de l'incapacité. C'est un voyage qui essaie de situer la cécité dans le contexte 
de résistances localisées: organismes et histoires qui revendiquent des cultures moins certaines de leurs propres sens.

ÍNDICE

Mots-clés: Mozambique, Cécité, incapacite, Sud

Palavras-chave: Moçambique, cegueira, deficiência, Sul

Keywords: Mozambique, blindness, disability, South

\section{AUTOR}

\section{BRUNO SENA MARTINS}

Centro de Estudos Sociais da Universidade de Coimbra bsenamartins@ces.uc.pt 